\title{
Role of Online Supportive Environment in Professional Development of In-service Teachers - Case of TELMAE
}

\author{
Zdena Lustigova \\ Charles University Prague, Czech Republic \\ lustigo@plk.mff.cuni.cz
}

\begin{abstract}
The paper provides a structured overview drawing on the results of the first four years of a country-wide activity focused on professional development of science teachers. This activity, organized by the Laboratory of Distance Education, Charles University in Prague within the framework of the State Information Policy (SIP) in Education Program, started in 2001, and it has become one of the top online learning activities in the country. The paper introduces the whole developed system of in-service teacher training on a "voluntary basis" and focuses on the TELMAE Science Teachers' Online Supportive Environment, developed also at the Laboratory of Distance Education at Charles University. The TELMAE supportive environment incorporates several features and communication, information, monitoring and controlling tools used for management and coordination of distributed systems of online courses. The key factors of the project are discussed at the end of the paper.
\end{abstract}

\section{The state information policy in education program - outcomes}

The government of the Czech Republic has adopted formal public policies, in particular the State Information Policy (SIP) in Education, aimed at moving its society from a post-industrial model to an information and knowledge-based society. "The basic objective of the state information policy is to foster and develop an information society and thereby to create the prerequisites for improving the quality of life of individual citizens...." [1]. The adaptation will come through expanded use of computers and their attendant technologies, such as the internet and networking, by all governmental sectors, including education.

In short, the initiative is to serve as a modernizing influence for Czech society as well as serving its global interests by bringing the country in line with European Commission initiatives. 


\subsection{State information policy in education}

One of the general aims is the inclusion of ICT in the education system, which is supposed to enable the development of a real Information Society. From this perspective, the Ministry of Education's main strategies are [2]:

1. Provision of schools and libraries with computers connected to the Internet.

2. Presence of an ICT coordinator in each school to help teachers and pupils use the technology as a resource for teaching and learning.

3. A shift in emphasis in teacher training, moving from a methodology concerned with the transmission of information to one concerned with problem-solving and greater emphasis on the use of ICT.

4. Introduction of programs for lifelong learning.

5. Introduction of programs to encourage teachers, researchers and manufacturers to discover efficient ways of using ICT.

6. Analysis and assessment of ICT policy.

In the following we will focus mainly on teacher education, in service training and other ways of professional development with respect to the main objective - to emphasize effective use of ICT in the classroom.

\subsection{The three-level pyramidal concept}

The key and the most surprising fact are that the SIP In Education program assumed the training of more then 200,000 teachers, including those at the pre-primary education level, within approximately 3-4 years. That is why the State Information Policy adopted the three-level pyramidal model for in-service teacher training:

1. The basic level has been offered to in service teachers since 2002 with the main focus on obtaining basic ICT skills and knowledge on a level comparable to the ECDL (word-processing, calculus, spreadsheets, browsing and effective searching for information, etc.).

2. The intermediate level ("P"-level courses) is more conceptual, subject oriented and focused mainly on the use of ICT in the classroom. The intermediate level, again, has been offered to all teachers, but only $25 \%$ of them will get funding from the budget of the SIP.

3. The specialized courses ("S"-level courses) are focused on specific topics and teachers' needs.

\subsection{ICT in science modules}

Science represents only about one third of the intermediate section $\mathrm{P}$ ("P "-level courses) and of course a part of the specialized section $S$ ("S"-level courses). The laboratory of Distance Education, Charles University in Prague, became the official SIP in Education Program guarantor for the science modules in 2002. The responsibilities were the following:

- To manage the training of approximately 10,000 in-service physics teachers in the period of three years (this represents the training of hundreds of tutors, development of a reliable supportive environment for disseminating information, for efficient communication, for registration and payment, etc.). 
- To guarantee the quality of the conceptual and content scheme and supportive materials, and the reliability of the online learning environment, including the learning object repositories.

- To guarantee the quality of the course outcomes (public accessibility and control). The guarantor is responsible for reviewing and publishing all final projects, which requires the development and providing of a reliable webbased publishing environment, the management of editorial boards and controlling the workflow.

The organizational, conceptual and content schemes of "P" level courses within the SIP in Education Program vary a lot. In the following we present the "ICT in Science" courses scheme.

In the case of ICT in science the best participants of "P" level courses might become lecturers under some special conditions and requirements. The teachers, who fill the requirements may organize their own courses, both the face-to-face and online parts. To ensure the quality, reliability and permanent accessibility of the whole training system, the online part is provided by the laboratory as a guarantor, the course runs are also under the supervision of the course guarantor; and the course outcomes are under public control (the participants' and lecturers' projects must be accessible by the public).

\section{TELMAE online supportive and publishing environment}

Students (in-service teachers) interact with the supportive environment of TELMAE throughout the whole course. The supportive environment TELMAE includes

1. different kinds of sources: databases of learning objects (so called Learning Object Repository); large variety of open edited databases filled in with different kind of useful information; online journals, tools for publishing, editing and reviewing (cross review).

2. a large variety of tools: tools for communication (both synchronous and asynchronous); tools for monitoring and controlling; tools for online registration, etc.

3. various other services and tools according the user role.

Management of the online parts of the courses, communication and feedback are provided by the Learning Space system (pilot runs also in Moodle Open Source LMS). 


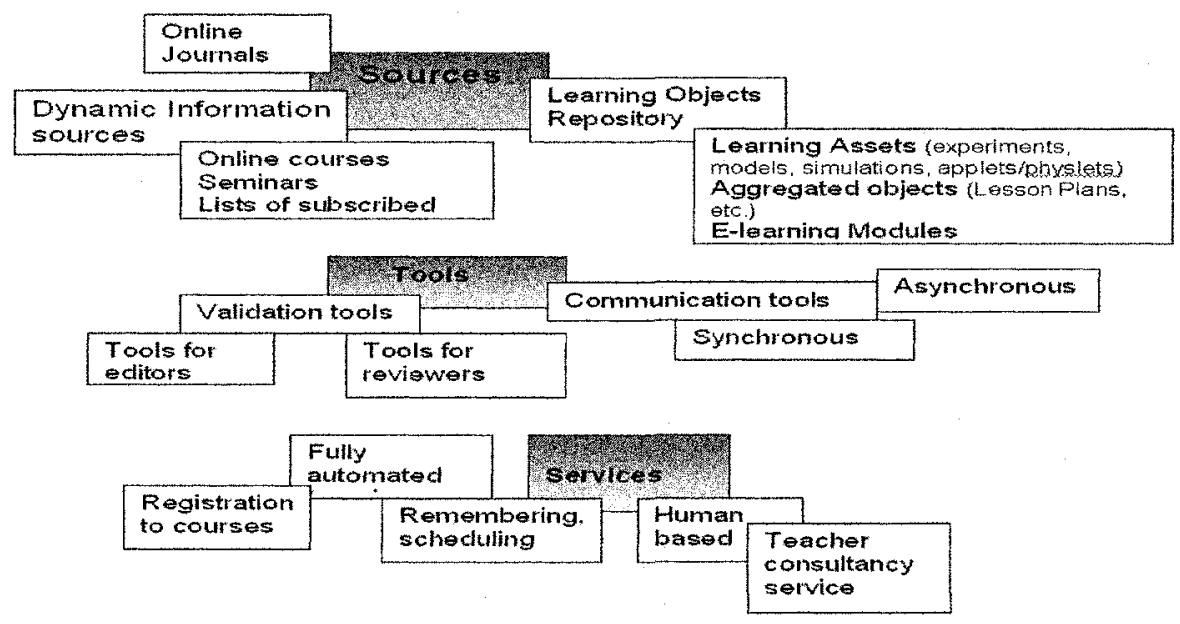

Figure 7. The basic scheme of the Telmae LOR and supportive environment

The online supportive environment TELMAE serves as a reliable source of information (in the Czech language) for students, as well as an environment where it is possible to publish one's own ideas - e.g., "recipe" simple experiments or lesson plans.

\section{Selected outcomes in particular}

More than five hundred students/teachers' projects have already been published on the TELMAE Learning Object Repository EDUPORT. Each student's work (lesson plan) is reviewed by two independent reviewers, in the same way as all the work done or contributed by common users, contracted authors and "P" level course instructors. In the case of physics and chemistry, reviewers are selected from physics and chemistry experts and experienced teachers of each subject area or teachers with long-term practice. Not all contributed projects are approved by the reviewers; so far one-half of the students' projects have been published.

\section{Conclusions - experience}

In-service teachers do not seem to have major problems with laboratory work done during seminars or with managing the virtual environment, either the supportive environment or the online course itself. Students' attitudes differ though, primarily because of psychological barriers and distance from the study (insufficient selfdiscipline). Often it is also a slow internet connection that causes problems in the online part of study. Despite these issues, the majority of students are able to complete the courses successfully. Some of the older students manage to overcome the above mentioned barrier for the first time during the course, and since they are well experienced teachers, their results then become examples for other students (see contributed projects on TELMAE). One of the major mistakes observed is students' 
"effort" to use ICT in class just for the sake of using it, no matter whether it has any contribution to learning or not. Overall, it is crucial to pay attention to expertise, active constructivist approach to learning and "sensitive" incorporation of ICT to appropriate areas and learning situations.

\section{References}

1. State Information Policy - The Road To An Information Society. Czech Republic. 27 May $2004<$ http://www.vlada.cz/1250/eng/vrk/rady/rady.htm>.

2. Elearningeuropa.info - National Policies - Czech Republic. 27 May 2004 $<\mathrm{http}: / / \mathrm{www}$.elearningeuropa.info/index.php?lng=l>. 